\title{
Modulation of respiratory dendritic cells during Klebsiella pneumonia infection
}

\author{
Holger Hackstein ${ }^{1 *}$, Sabine Kranz ${ }^{1}$, Anne Lippitsch', Andreas Wachtendorf ${ }^{1}$, Olivia Kershaw², Achim D Gruber², \\ Gabriela Michel ${ }^{1}$, Jürgen Lohmeyer ${ }^{3}$, Gregor Bein ${ }^{1}$, Nelli Baal ${ }^{1}$ and Susanne Herold ${ }^{3}$
}

\begin{abstract}
Background: Klebsiella pneumoniae is a leading cause of severe hospital-acquired respiratory tract infections and death but little is known regarding the modulation of respiratory dendritic cell (DC) subsets. Plasmacytoid DC (pDC) are specialized type 1 interferon producing cells and considered to be classical mediators of antiviral immunity.

Method: By using multiparameter flow cytometry analysis we have analysed the modulation of respiratory DC subsets after intratracheal Klebsiella pneumonia infection.

Results: Data indicate that pDCs and MoDC were markedly elevated in the post acute pneumonia phase when compared to mock-infected controls. Analysis of draining mediastinal lymph nodes revealed a rapid increase of activated $\mathrm{CD}_{103^{+}} \mathrm{DC}, \mathrm{CD} 11 \mathrm{~b}^{+} \mathrm{DC}$ and MoDC within $48 \mathrm{~h}$ post infection. Lung pDC identification during bacterial pneumonia was confirmed by extended phenotyping for 120G8, mPDCA-1 and Siglec-H expression and by demonstration of high Interferon-alpha producing capacity after cell sorting. Cytokine expression analysis of ex vivo-sorted respiratory DC subpopulations from infected animals revealed elevated Interferon-alpha in pDC, elevated IFN-gamma, IL-4 and IL-13 in CD103 ${ }^{+}$DC and IL-19 and IL-12p35 in CD11 b DC subsets in comparison to CD11 $\mathrm{c}^{+} \mathrm{MHC}$-class $\|^{\text {low }}$ cells indicating distinct functional roles. Antigen-specific naive CD4 ${ }^{+} \mathrm{T}$ cell stimulatory capacity of purified respiratory DC subsets was analysed in a model system with purified ovalbumin $T$ cell receptor transgenic naive $C D 4^{+}$responder T cells and respiratory DC subsets, pulsed with ovalbumin and matured with Klebsiella pneumoniae lysate. $\mathrm{CD}_{103^{+}} \mathrm{DC}$ and $\mathrm{CD} 11 \mathrm{~b}^{+} \mathrm{DC}$ subsets represented the most potent naive $\mathrm{CD} 4^{+} \mathrm{T}$ helper cell activators.

Conclusion: These results provide novel insight into the activation of respiratory DC subsets during Klebsiella pneumonia infection. The detection of increased respiratory PDC numbers in bacterial pneumonia may indicate possible novel pDC functions with respect to lung repair and regeneration.
\end{abstract}

Keywords: Klebsiella pneumonia, Pneumonia, Plasmacytoid dendritic cells

\section{Introduction}

Klebsiella spp. are gram-negative bacteria and important opportunistic pathogens causing life-threatening nosocomial infections [1,2]. Typical clinical presentations of Klebsiella pneumonia are nosocomial respiratory tract infections, urinary tract infections, infections of the bloodstream and premature infant intensive care unit infections [1,3-6]. Multidrug resistant Klebsiella pneumonia strains are becoming an increasingly relevant

\footnotetext{
* Correspondence: Holger.Hackstein@immunologie.med.uni-giessen.de ${ }^{1}$ Institute for Clinical Immunology and Transfusion Medicine, Justus-Liebig-University Giessen, Member of the German Center for Lung Research (DZL), Langhansstr. 7, D-35392, Giessen, Germany

Full list of author information is available at the end of the article
}

medical problem worldwide with limited clinical treatment options [7-11]. Therefore, there is a medical need for the development of novel therapeutic strategies in addition to classical antibiotic therapies. However, despite the clinical significance of Klebsiella pneumonia, little is known regarding the modulation of respiratory dendritic cells (DC) subsets during lower respiratory tract infection with Klebsiella spp.

DC are central instigators of innate and adaptive immunity regulating both inflammation and activation of antigen-specific lymphocytes [12-14]. Based on the expression of different surface markers respiratory DC can be separated in at least four subsets, plasmacytoid DC

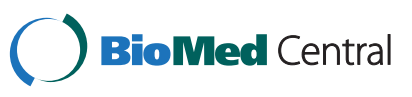


(pDC), $\mathrm{CD}_{103^{+}} \mathrm{DC}, \mathrm{CD} 11 \mathrm{~b}^{\mathrm{hi}} \mathrm{DC}$ and monocytic DC (MoDc) [15-19]. PDC represent the most potent producers of Interferon-alpha and therefore play critical roles in antiviral immunity [20-23]. Additionally, it has been reported that $\mathrm{pDC}$ sense skin injury and promote wound healing through type I interferon suggesting a novel role for these professional antigen presenting cells [24].

Respiratory $\mathrm{CD}_{103}{ }^{+} \mathrm{DC}$ have been reported to be involved in the development of airway hyperresponsiveness and to play important roles in naive $\mathrm{CD} 8^{+} \mathrm{T}$ cell activation and antiviral respiratory immunity $[25,26]$. With respect to bacterial respiratory tract infections, $\mathrm{CD} 103^{+} \mathrm{DC}$ have been shown to play a key role for $\alpha$-Galactosylceramide -mediated protection against lethal Streptococcus pneumonia infection [27]. Together with $C D 11 b^{\text {hi }}$ DC and

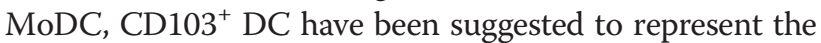
major migratory DC subsets promoting naive $C D 4^{+}$and $\mathrm{CD}^{+} \mathrm{T}$ cell activation in the draining lymph nodes [15,26,28-30].

We have used multicolor flow cytometry to dissect and quantitate respiratory DC subsets during murine Klebsiella pneumonia. Additionally, respiratory DC subsets were purified by cell sorting from Klebsiella-infected animals and analysed for cytokine mRNA expression. The functional $\mathrm{CD}^{+}$naive $\mathrm{T}$ cell stimulatory capacity of purified respiratory DC subsets was determined in vitro after Klebsiella pneumonia lysate stimulation of ovalbumin-pulsed DCs and ovalbumin (OVA) T-cell receptor (TCR)-transgenic naive $\mathrm{CD} 4^{+}$responder $\mathrm{T}$ cells.

\section{Materials and methods}

\section{Mice and treatment protocol}

Specific-pathogen-free C57BL/6 (C57BL/6NCrl) and OVA TCR transgenic C57BL/6-Tg(TcraTcrb)425Cbn/J mice (18-21 g) were purchased from Charles River, Sulzfeld, Germany and maintained under specific-pathogen-free conditions. The transgenic mice express the TCR that pairs with the CD4 coreceptor and is specific for chicken OVA 323-339 in the context of MHC-class-II (I-A $\left.{ }^{b}\right)$. Wild-type mice were infected intratracheally with Klebsiella pneumonia serotype $2\left(1 \times 10^{4}\right.$ in sterile PBS in $\left.50 \mu \mathrm{l}\right)$ as described [31] and analysed at the indicated timepoints. Mock-infected controls were treated identical but received sterile $\mathrm{NaCl}$ instead of Klebsiella pneumonia. Analyses were performed after approval of the regional authority board City of Giessen (\#71/2009 and \# A25/2009).

\section{Lung and mediastinal lymph node preparation}

Lung single cell suspension were prepared after enzymatic digestion as described in detail elsewhere [16,17]. Absolute respiratory cell counts were enumerated with the trucount method (BD Biosciences, Germany) as described $[16,17]$. Trucount tubes contain a known number of fluorescent beads allowing the flow cytometer software to calculate absolute cell counts. Single cell suspension from mediastinal lymph nodes (MLN) were minced and digested in RPMI 1640/10\% FCS (PAA laboratories, Germany) with $10 \mathrm{U} / \mathrm{ml}$ DNase and $1 \mathrm{mg} / \mathrm{ml}$ Collagenase A (Roche, Germany) for $30 \mathrm{~min}$ at $37 \mathrm{C}$, resuspended with a $20 \mathrm{G} 1 \frac{1}{2}$ canule $(0.9 \times 40 \mathrm{~mm}$, BD, Germany), mashed through a $70 \mu \mathrm{m}$ cell strainer and washed two times with HBSS (7 min, 400 g; PAA laboratories, Germany).

\section{Flow cytometry and fluorescent activated cell sorting}

Cellular phenotyping was performed on a BD CantoII flow cytometer and fluorescent activated cell sorting was performed on a BD ARIA3 cell sorter (Becton Dickinson, San Jose, CA, USA). The following fluorochrome-labelled monoclonal antibodies conjugated to FITC, PE, PeCy7, PerCPCy5.5, APC, APC-Cy7, Pacific Blue and appropriate isotype controls were used for surface staining according to the manufacturer's instructions: CD11b, CD11c, CD45, CD64, CD86, CD103, CD274, I-A ${ }^{\mathrm{b}}$, GR-1, Ly-6G, F4/80, NK1.1, FceRIa (MAR-1), Siglec-H, Siglec-F (BD Biosciences, Germany), mPDCA-1 (MiltenyiBiotec, Germany), 120G8 (Dendritics, France). Surface mAb or isotype staining time was $30 \mathrm{~min}$ on ice and cells were washed with staining buffer ( $1 \times$ HBSS, PAA, Germany) at $400 \mathrm{~g}, 5 \mathrm{~min}$, room temperature (RT) before analysis. The number of acquired events was $\geq 500,000$ after surface stainings.

Highly purified naive OVA TCR transgenic CD4+ T cells were prepared from spleen cell suspensions. First, MHC-class-II and CD19 positive cells were depleted with magnetic-beads (MiltenyiBiotec) on an AutoMACS magnetic-bead sorter (MiltenyiBiotec) and subsequently naive CD4+ T cells were sorted on the ARIA3 sorter after surface staining with a lineage cocktail (CD8a, CD25, CD11b, CD11c, CD45R, CD49b) and CD62L mAbs to identify naive $\mathrm{T}$ cells . The post sort purity of $\mathrm{CD}^{+} \mathrm{CD}^{+} 2 \mathrm{~L}^{+} \mathrm{CD} 44^{\text {dim }}$ cells was $>98 \%$. Respiratory DC subsets were sorted on the ARIA3 cell sorter (purity $>98 \%$; Additional file 1: Figure S1). Viability of cells was $>90 \%$ as indicated by sytox blue (Life Technologies, Germany) staining. All mabs were ordered from Biolegend, Germany unless indicated otherwise.

\section{Gating strategy for respiratory leukocyte subset discrimination}

The gating strategy for the respiratory subsets, including respiratory DC subsets has been described recently in detail $[17,19]$. Briefly, respiratory leukocytes were identified by CD45 expression. Out of the CD45+ cells, neutrophils were identified by GR $1^{\text {bright }} \mathrm{CD} 11 \mathrm{~b}^{\text {bright }}$ expression. Subsequently, out of the neutrophil negative fraction, macrophages were identified as SiglecF $\mathrm{F}^{++} \mathrm{F} 4 / 80^{+}$double positive cells. Respiratory dendritic cells (DC) were identified according to $\mathrm{CD} 11 \mathrm{c}^{+}$Siglec- $\mathrm{F}^{\text {neg }} \mathrm{NK} 1.1^{\text {neg }}$ expression to 
exclude autofluorescent macrophages and NK cells and further dissected into pDC (120 g8 $\left.{ }^{+} \mathrm{CD}_{11 \mathrm{~b}^{\text {neg }}}\right), \mathrm{CD} 103$ $\mathrm{DC}\left(\mathrm{CD} 103^{+} \mathrm{CD} 11 \mathrm{~b}^{\text {neg }}\right)$ and $\mathrm{CD} 11 \mathrm{~b}$ DC $\left(\mathrm{CD}_{11} \mathrm{~b}^{+}\right.$ $\left.C D 103^{\text {neg }}\right)$. MoDC were discriminated from CD11b DC based on CD64 and MAR1 expression as described recently [19]. In MLN, cells were additionally stained for CCR7 to identify migrating CD103 DC, CD11b DC and MoDC (Additional file 2: Figure S2). Fluorescence minus one (FMO) isotype controls were used regularly for proper identification of marker positive subsets.

\section{Naive CD4+ $\mathrm{T}$ cell proliferation assay}

Purified DC subsets $\left(1 \times 10^{4} /\right.$ well $)$ were incubated in culture medium $( \pm 100 \mu \mathrm{g} / \mathrm{ml}$ endotoxin-free OVA; Hyglos, Germany) with carboxyfluorescein diacetate succinimidyl ester (CFSE) labeled purified naive $\mathrm{CD}^{+}$OVA TCR transgenic responder cells $\left(1 \times 10^{5} /\right.$ well $)$ in 96 well round bottom wells (Greiner, Germany) for five days. Klebsiella pneumonia lysate was prepared as described [16] and added at a concentration of $10 \mathrm{ul} / \mathrm{ml}(1: 100)$ $4 \mathrm{~h}$ after OVA for DC maturation. DC maturation with different Klebsiella pneumonia lysate dilutions (1:101:500) was controlled by flow cytometry analysis of CD86 and MHC-class II expression on respiratory DC (Additional file 3: Figure S3). Culture medium consisted of RPMI 1640 with L-glutamine (PAA Laboratories), penicillin/streptomycin (PAN Biotech), sodiumpyruvate (Gibco), nonessential aminoacids (Sigma), Hepes buffer (Gibco), and 10\% heat inactivated FCS (PAA Laboratories). CFSE labeling concentration was $1 \mu \mathrm{M}$ and was performed according to the manufacturer instructions (Vybrant CFDA-Cell Tracer kit, Molecular probes, Eugene, USA). Positive controls consisted of in vitro bone-marrow-derived DC (expanded as described [32]) with OVA and responder cells. Negative controls consisted of responder cells cultured with OVA in the absence of stimulator cells and responder cells cultured with stimulator cells in the absence of ovalbumin. Proliferation was quantitated by measurement of CFSE-dilution in responder cells by flow cytometry as described [33]. Positive bone-marrow-derived control DC pulsed with OVA induced naive CD4+ responder proliferation rates of $>80 \%$. Proliferation rates in negative controls were $<5 \%$.

\section{IFN- $\alpha$ induction and quantitation}

IFN $-\alpha$ production was stimulated with CpG ODN2216 $(6 \mu \mathrm{g} / \mathrm{ml})$ in sorted cell subsets after overnight culture in RPMI 1640 with 10\% FCS (PAA Laboratories). IFN- $\alpha$ was quantitated in cellular supernatants on the FACS CantoII flow cytometer in parallel to recombinant cytokine standards by using the cytometric bead assay technology according to the manufacturer instructions (Flowcytomix, eBioscience, Germany).

\section{Cytokine mRNA quantification}

Cytokine mRNA expression was determined in sorted respiratory DC subsets from Klebsiella-infected animals by quantitative RT-PCR on an ABI TaqMan StepOne plus real time PCR system (Applied Biosystems, Germany) with the $\mathrm{RT}^{2}$ profiler PCR assay (Qiagen, Germany). RNA was isolated with RNeasy Mini Kit (Qiagen) and transcribed into cDNA with the $\mathrm{RT}^{2}$ Preamp cDNA Synthesis Kit (Qiagen) according to the manufacturer instructions.

\section{Statistical analyses}

The significance of differences between groups were analysed by one-way ANOVA and Tukey post-test for multiple comparisons. A p-value $<0.05$ was considered significant. Statistical analyses were performed with Prism 5.02 software (Graphpad software, Inc., USA).

\section{Results}

\section{Respiratory dendritic cell subsets and Klebsiella} pneumonia infection

By using multiparameter flow cytometry we analysed absolute and relative changes of major respiratory leukocyte populations including neutrophils, macrophages and DC during acute ( $48 \mathrm{~h} \mathrm{p.i.)}$ and post acute (d5 p.i.) respiratory Klebsiella pneumonia infection (Figure 1A). Total DC were further dissected by flow cytometry into four major

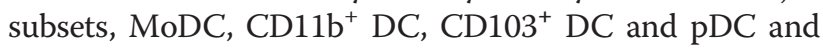
relative $\mathrm{DC}$ subset frequencies and absolute $\mathrm{DC}$ subset numbers were calculated (Figure 1B,C; Figure 2). Results indicated that total respiratory DCs in general were increased both at $48 \mathrm{~h}$ p.i and $\mathrm{d} 5$ p.i. but the dissection of DC subsets revealed different patterns for each subpopulation (Figure 1B,C). Early after infection ( 48 h p.i.), relative $\mathrm{CD}_{103^{+}} \mathrm{DC}$ numbers were significantly decreased in accordance with their reported function to rapidly transport antigen to regional lymph nodes [34]. Unexpectedly, with respect to $\mathrm{pDC}$ representing the rarest subset, we found a marked relative and absolute elevation of respiratory pDC numbers in the post acute phase of Klebsiella pneumonia (d5 p.i.) when compared to mock-infected controls ( $\mathrm{p}<$ 0.01 ; Figure $1 \mathrm{~B}, \mathrm{C}$ ). Additionally, absolute numbers of respiratory $\mathrm{CD}_{11 b^{+}} \mathrm{DC}$ and MoDC were markedly increased at $48 \mathrm{~h}$ and day 5 p.i. (Figure 1C). The massive leukocyte subset changes detected by flow cytometry correlated well with histopathology exhibiting extensive cellular infiltrates and cellular necrosis indicating severe bacterial pneumonia (Figure 3).

\section{Confirmation of functional respiratory $\mathrm{pDC}$ during Klebsiella pneumonia infection by extended phenotyping and cell sorting}

Given the fact, that Klebsielle pneumonia infection induced major respiratory inflammation we discussed the 


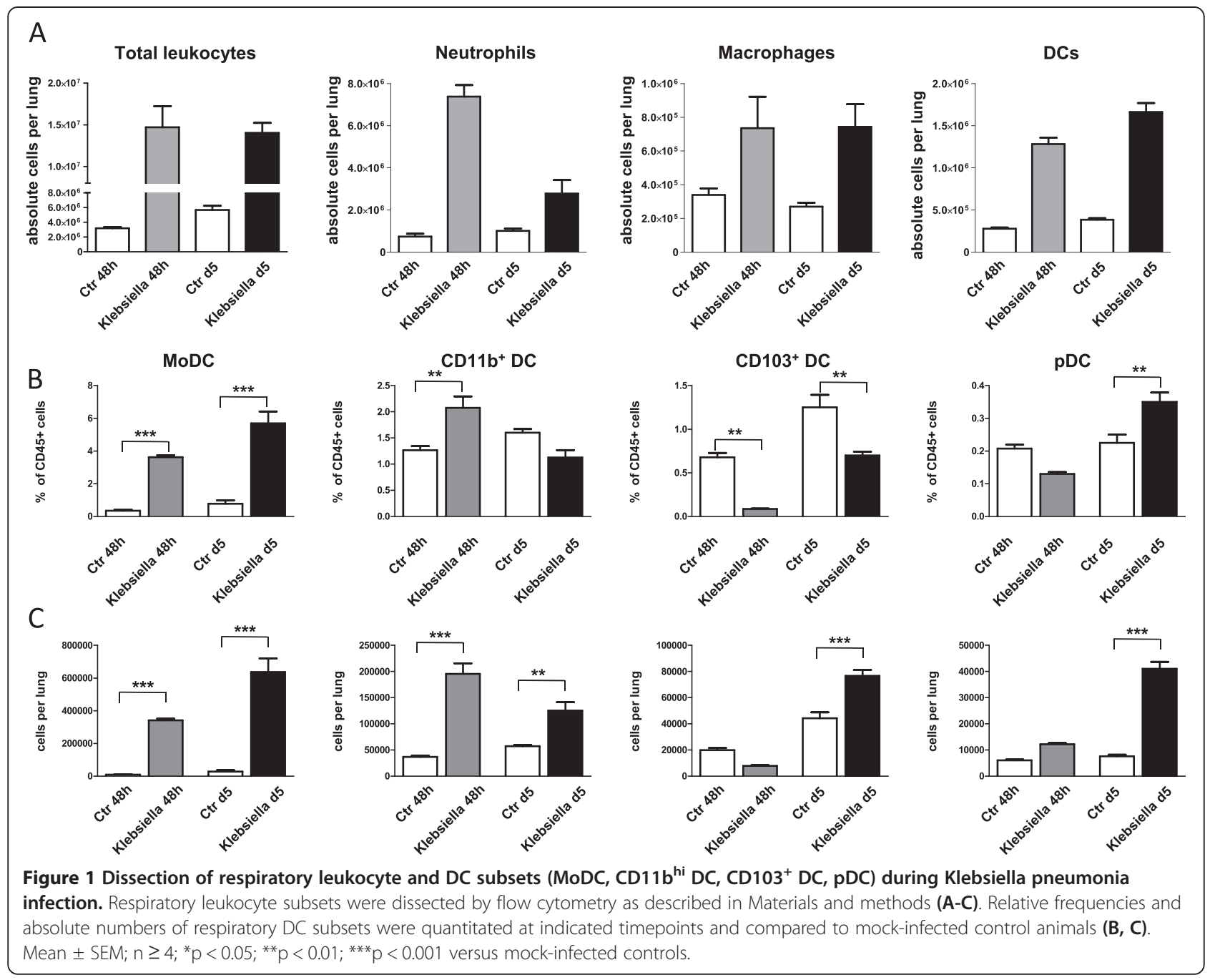

possibility that $\mathrm{pDC}$ identification by flow cytometry might have been confounded by unspecific surface marker upregulation due to the inflammatory process. Accordingly, we extended pDC surface marker analysis on Klebsiella-infected animals (d5 p.i.) and included Siglec-H and mPDCA-1 mAb surface staining (Figure 4A). These experiments confirmed expression of Siglec-H and mPDCA-1 on respiratory pDC during Klebsiella pneumonia. Additionally, in order to use an independent functional method we sorted lung $120 \mathrm{G}^{+}{ }^{+} \mathrm{CD}_{11 b^{-}} \mathrm{CD}_{11 \mathrm{c}^{+}} \mathrm{CD} 45^{+}$putative respiratory pDC (d5 p.i.) and tested their capacity to produce IFN- $\alpha$. These experiments confirmed high IFN- $\alpha$ producing capacity in respiratory pDC from Klebsiellainfected animals in comparison to non-pDC control fractions (Figure 4B). These data demonstrated that the immunophenotypically identified pDC during bacterial pneumonia, represented viable and functional respiratory $\mathrm{pDC}$.

\section{Distinct cytokine expression of purified respiratory DC} subsets during Klebsiella pneumonia infection

To determine the cytokine expression of respiratory DC subsets during Klebsiella pneumonia we sorted pDC, $\mathrm{CD}_{103^{+}} \mathrm{DC}, \mathrm{CD} 11 \mathrm{~b}^{+} \mathrm{DC}$ and $\mathrm{CD} 11 \mathrm{c}^{+}$MHC-class $\mathrm{II}^{\mathrm{low}}$ cells from Klebsiella-infected animals (d5 p.i.) to high purity $(>98 \%)$ and analysed mRNA expression by quantitative real time RT-PCR. Controls included genomic DNA controls, reverse transcriptase controls and positive PCR controls. Relative cytokine expression of $\mathrm{pDC}$,

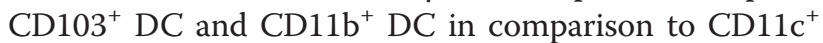
MHC-class $\mathrm{II}^{\text {low }}$ cells was calculated by the $2^{(-\Delta \Delta}$ CT) method to indicate differences between the subsets (Figure 5). $\mathrm{CD}_{11 \mathrm{c}^{+}} \mathrm{MHC}$-class $\mathrm{II}^{\text {low }}$ cells were selected as common reference because we wanted to display relative cytokine expression differences in-between pDC, $\mathrm{CD}_{103^{+}} \mathrm{DC}$ and $\mathrm{CD} 11 \mathrm{~b}^{+}$DC. Respiratory pDC exhibited elevated IFN- $\alpha$ expression indicating activation during bacterial pneumonia. In contrast, $\mathrm{CD}_{103^{+}} \mathrm{DC}$ 


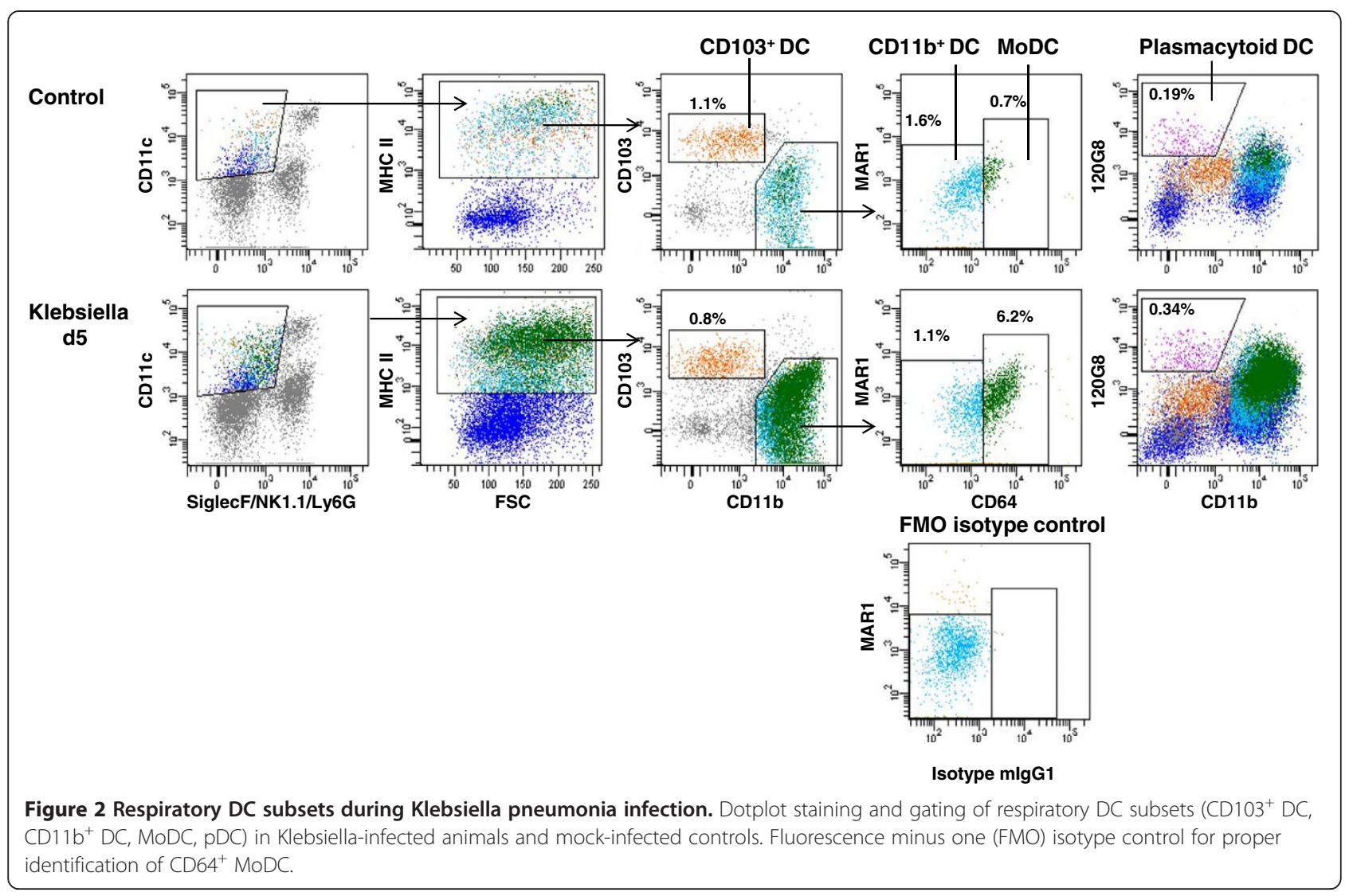

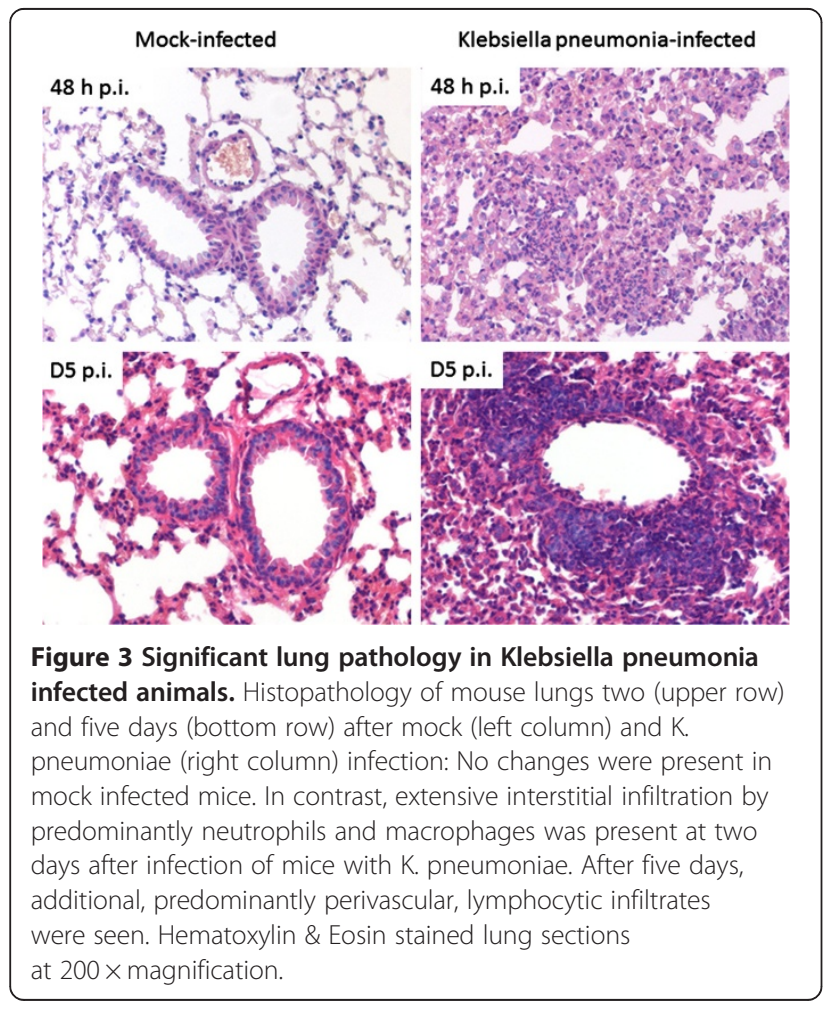

exhibited increased IFN- $\gamma$, IL-4 and IL-13 expression, whereas CD11b DC showed elevated expression of IL12p35 and IL-19 in comparison to CD11c ${ }^{+}$MHC-class II low cells.

\section{Different modulation of MHC class II, CD86 and CD274 expression on respiratory $D C$ subsets during acute Klebsiella pneumonia infection}

Expression of MHC-class II, CD86 and CD274 represent functionally important molecules of antigen presenting cells to regulate $\mathrm{CD} 4^{+} \mathrm{T}$ responder cell activation. Accordingly, we quantitated MHC-class II, CD86 and CD274 surface expression on total respiratory DC and DC subsets to determine the modulation during acute and post-acute respiratory Klebsiella pneumonia infection (Figure 6A,B). Results demonstrated that at $48 \mathrm{~h}$ p.i. and at d5 p.i. respiratory MoDC and to a lesser extent $\mathrm{CD}_{11 \mathrm{~b}^{+}} \mathrm{DC}$ from Klebsiella pneumonia-infected animals exhibited reduced MHC-class II expression. In contrast, costimulatory CD86 expression was markedly increased at $48 \mathrm{~h}$ p.i. on respiratory $\mathrm{CD} 103^{+} \mathrm{DC}$ and $\mathrm{CD}_{11} \mathrm{~b}^{+} \mathrm{DC}$ of infected animals when compared to mock-infected-controls. pDC and MoDC did not exhibit major CD86 expression changes at $48 \mathrm{~h}$ p.i. Moreover, MoDC exhibited at d5 p.i. reduced CD86 expression 
A

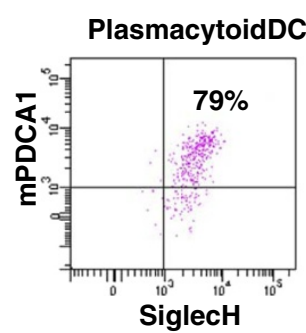

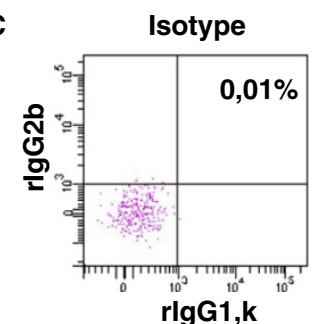

B

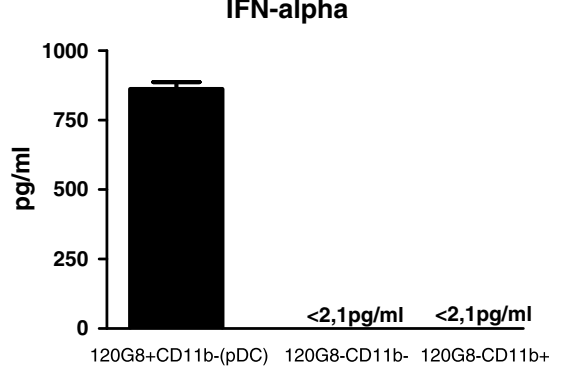

Figure 4 Confirmation of respiratory pDC identity during Klebsiella infection (d5 p.i.) by extended phenotyping and cell sorting. Identity of pDC during Klebsiella pneumonia was confirmed by additional phenotyping of CD11c +120 g8 + CD11 $b^{\text {neg }}$ cells for mPDCA-1 and Siglec-H in parallel with isotype controls (A). Functional ability of respiratory pDC from Klebsiella infected animals to produce IFN-alpha was confirmed by cell sorting and CPG ODN stimulation in comparison to control populations (B). Respiratory pDC during Klebsiella pneumonia are CD1 $1 b^{\text {neg }} 120 \mathrm{G}^{+}$Siglec- $\mathrm{H}^{+}$mPDCA-1 ${ }^{+}$cells $(\mathbf{A}, \mathbf{B})$ and exhibit the capacity to produce large amounts of IFN-a (B). Mean \pm SEM; $n \geq 3$.

which may be related to the differentiation of newly arrived DC. The immunoregulatory molecule CD274 was most markedly induced on CD11 $\mathrm{b}^{+} \mathrm{DC}$ and MoDC both at $48 \mathrm{~h}$ p.i. and $\mathrm{d} 5$ p.i. whereas expression on $\mathrm{CD}_{103^{+}} \mathrm{DC}$ and $\mathrm{pDC}$ was less affected. These results indicated, that respiratory DC subsets exhibited major heterogeneity with respect to MHC-class II, CD86 and CD274 expression during respiratory Klebsiella infection suggesting different functional capacity to activate responder $\mathrm{T}$ cells. These differences would have been masked, if respiratory DC were analysed as a single
$\mathrm{CD}_{11 c^{+}}$Siglec $\mathrm{F}^{\text {neg }} \mathrm{MHC}-\mathrm{II}^{+}$population without subset discrimination.

\section{Klebsiella pneumoniae-activated respiratory DC subsets} exhibit different naive $\mathrm{CD} 4^{+} \mathrm{T}$ cell stimulatory capacity In order to determine the naive $\mathrm{CD}_{4}^{+} \mathrm{T}$ cell stimulatory capacity of purified respiratory DC subsets activated by Klebsiella pneumonia we used an in vitro model system with CFSE-labelled OVA TCR transgenic $\mathrm{CD} 4^{+} \mathrm{T}$ helper cells as antigen-specific responder cells. Stimulatory respiratory DC subsets were sorted to high purity $(>98 \%$ for

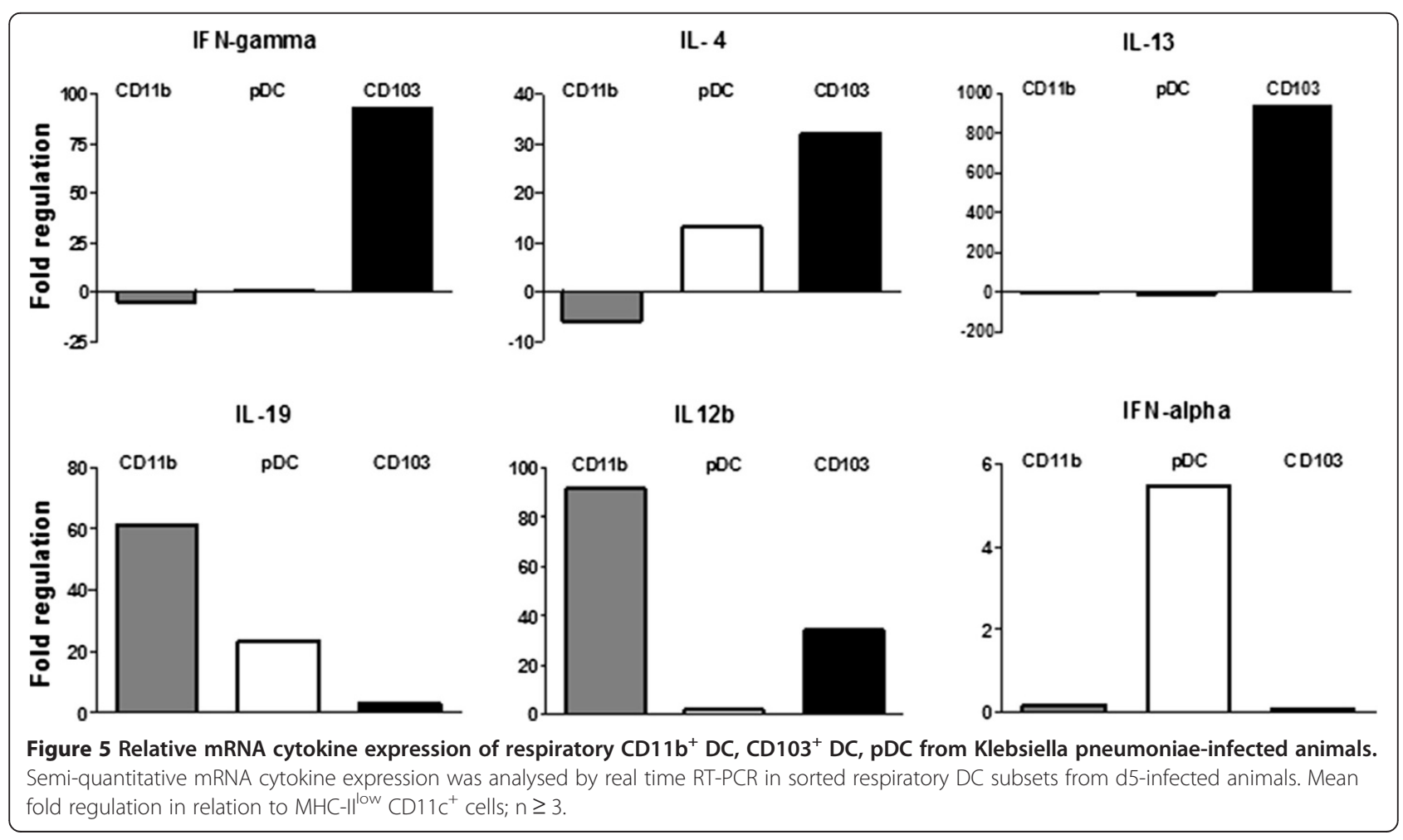




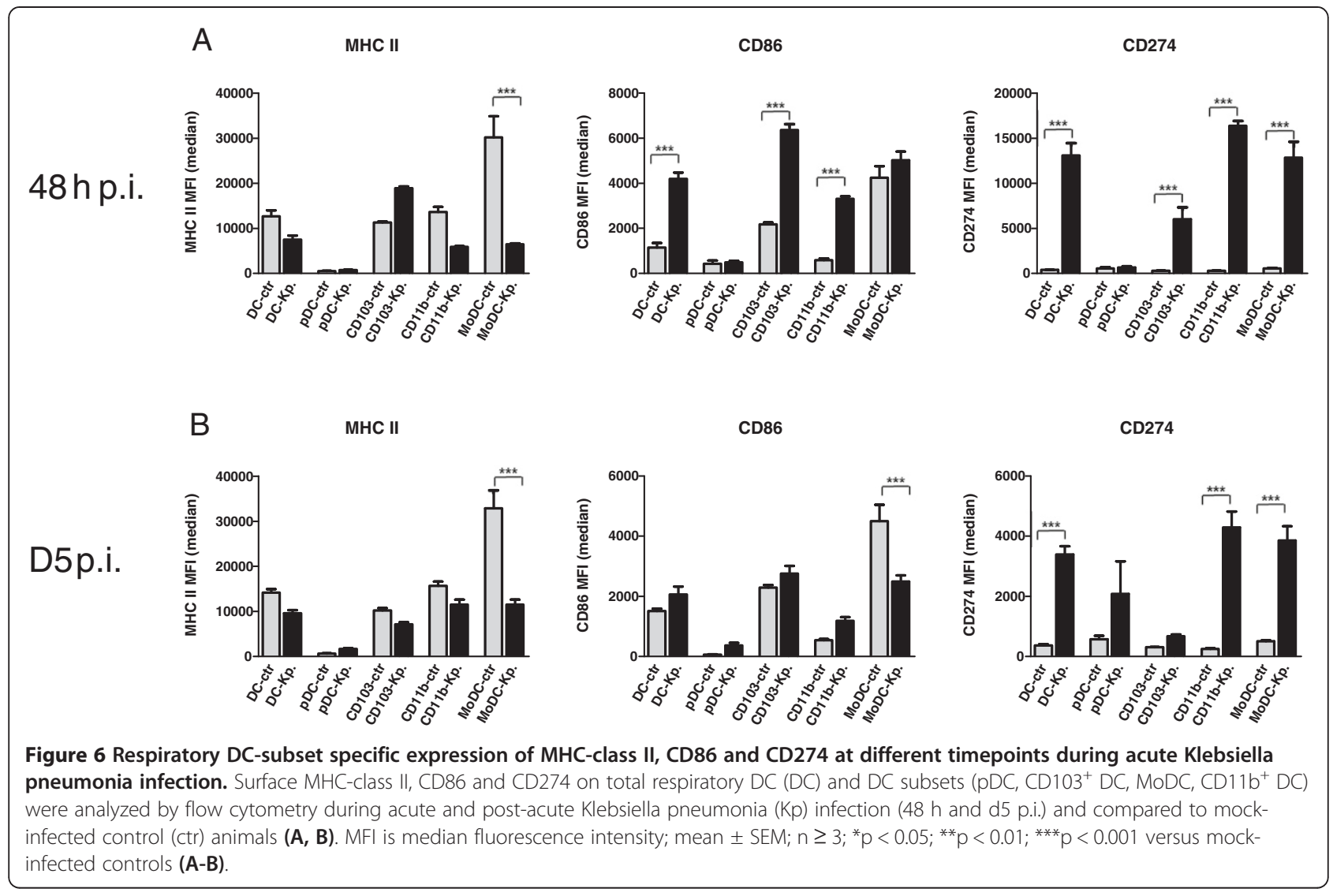

each subset) labelled with the model antigen OVA and matured with Klebsiella pneumonia lysate. Additional controls included sorted respiratory macrophages and granulocytes and in vitro bone-marrow-derived DC without OVA (negative control). Untouched naive $\mathrm{CD} 4^{+} \mathrm{TCR}$ transgenic responder cells were magnetic-bead sorted and the phenotype after sorting was controlled by surface CD4, CD62L and CD44 staining (purity >98\%). Results indicated that Klebsiella pneumonia-activated $\mathrm{CD}_{103}{ }^{+}$

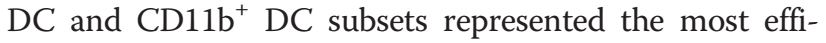
cient stimulators of purified naive CD4 $\mathrm{T}$ responder cells (Figure 7; mean proliferation rates $95 \%$ and $64 \%$, respectively). In contrast, Klebsiella pneumonia-activated pDC and $\mathrm{CD} 11 \mathrm{c}^{+} \mathrm{MHC}$-class $\mathrm{II}^{\text {low }}$ cells, as well as granulocytes and macrophages induced no or only minor naive CD4 $\mathrm{T}$ cell proliferation $(<5 \%)$. Interestingly, sorted DC subsets that were not activated with Klebsiella pneumonia induced comparable $\mathrm{CD}_{4}^{+} \mathrm{T}$ cell proliferation indicating that Klebsiella may induce both activatory and inhibitory effects on DC. Control experiments with cultures of DC $+\mathrm{CD} 4^{+} \mathrm{T}$ cells without OVA and $\mathrm{CD} 4^{+} \mathrm{T}$ cells + OVA without $\mathrm{DC}$ showed no responder cell proliferation and confirmed the antigen-specificity of the assay (Figure 7A,B). Naive $\mathrm{CD}^{+} \mathrm{T}$ cell stimulatory capacity of purified, Klebsiella activated respiratory DC subsets correlated closely with MHC-class II and CD86 expression of respiratory DC subsets from Klebsiella-infected animals (Figure 7) underlining the functional importance of MHC-class II and CD86 expression. Overall, these results indicated marked differences of Klebsiella-activated respiratory DC subsets to activate naïve $\mathrm{CD} 4^{+} \mathrm{T}$ cells.

\section{Rapid accumulation of activated $\mathrm{CD} 103^{+} \mathrm{DC}, \mathrm{CD} 11 \mathrm{~b}^{+} \mathrm{DC}$ and MoDC in the MLN}

Analysis of DC subset changes in the draining MLN revealed a marked increase of relative and absolute CCR7 ${ }^{+}$

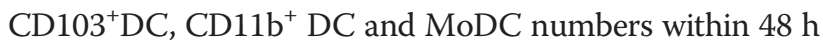
p.i. whereas absolute pDC numbers were elevated on D5 p.i. (Figure $8 \mathrm{~A}, \mathrm{~B}$ ). Phenotypic analysis of activatory CD86 expression indicated significant upregulation on $\mathrm{CD}_{103}{ }^{+}$

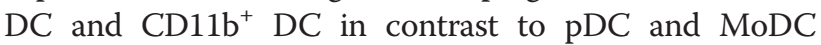
(Figure $8 \mathrm{C}$ ). Interestingly, MHC-class II expression was impaired to different extent on all DC subsets in comparison to mock-infected controls again suggesting that Klebsiella pneumonia infection may induce both activatory and inhibitory effects on antigen presenting cells.

\section{Discussion}

Klebsiella pneumoniae is a frequent multidrug-resistant emerging pathogen playing an increasingly important role in severe nosocomial infections $[7,8,10,11]$. DC are central regulators of innate and adaptive immunity against 
A
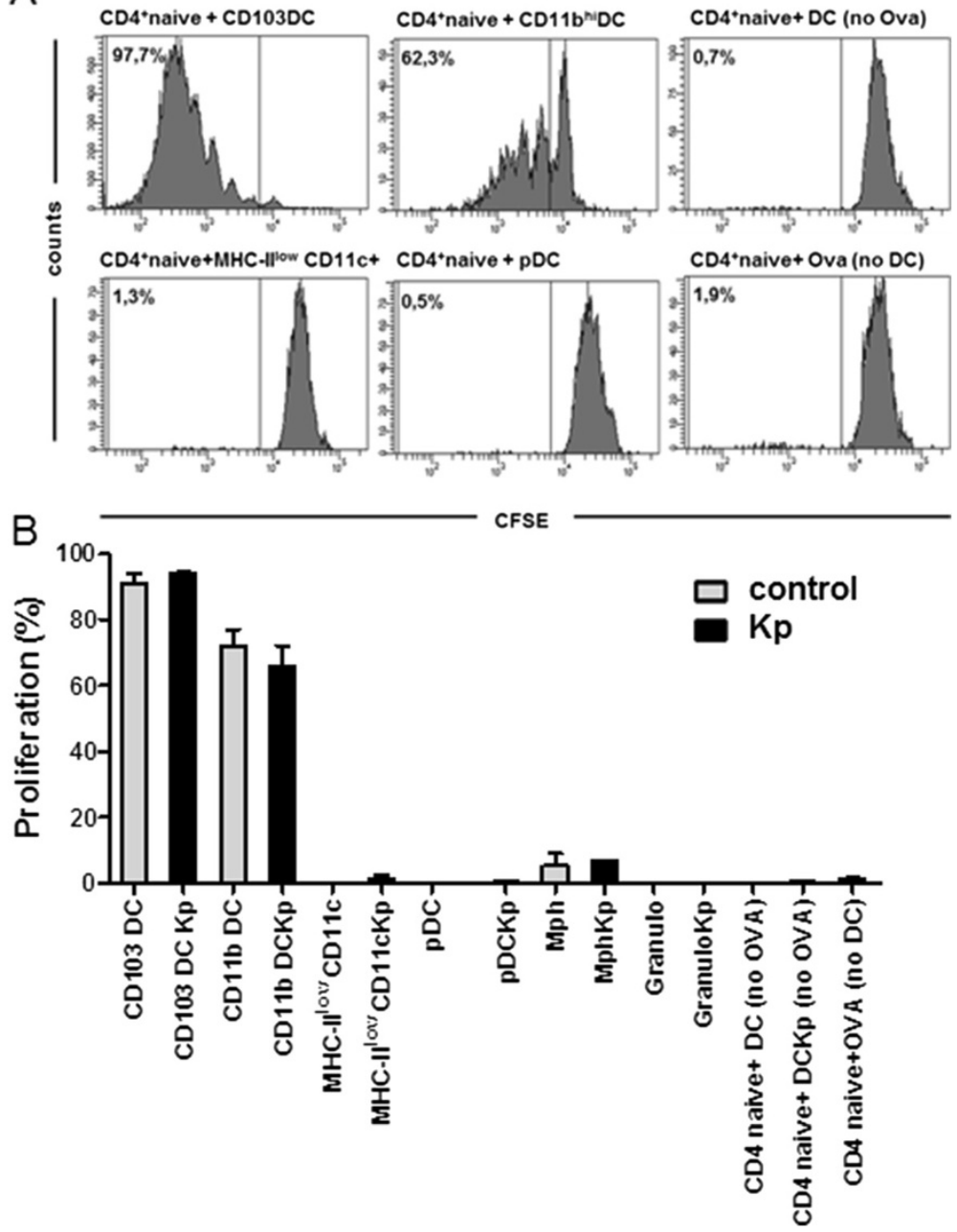

Figure 7 Different capacity of purified Klebsiella pneumoniae-stimulated respiratory DC subsets to activate OVA TCR-transgenic naive $\mathrm{CD}^{+}$responder T cells in a CFSE-dilution assay. Respiratory DC subsets were sorted to high purity (>98\%), pulsed with the model antigen OVA and matured with Klebsiella pneumoniae lysate (Kp). Naïve CD4 ${ }^{+}$responder T cells were sorted from OVA TCR transgenic animals and labeled with CFSE. Negative controls included DC without Klebsiella lysate (control), responder T cells cultured without DC (no DC) and DC-T cell co-cultures without OVA (no OVA). Proliferation was quantitated by CFSE-dilution of responder T cells (A,B). Mean \pm SEM; $n \geq 3$.

different kinds of pathogens [35,36,37]. Based on different developmental pathways, surface markers and tissue localizations, DC can be divided into distinct subsets exhibiting specific functions [38]. By using multiparameter flow cytometry and cell sorting we have determined the number and activation of respiratory DC subsets during experimental Klebsiella pneumoniae infection.

Subset-specific respiratory DC quantification of Klebsiellainfected animals showed that the rare $\mathrm{pDC}$ population were markedly elevated in the post acute disease phase. We confirmed the identity of functional respiratory pDC during bacterial pneumonia by extended phenotyping and demonstration of large IFN-alpha production capacity after cell sorting. Moreover, elevated IFNalpha mRNA expression was demonstrated in purified respiratory pDC sorted from Klebsiella-infected animals. Unexpectedly, cytokine mRNA analysis indicated IL-4 and IL-13 expression in CD103 DC and IL19 expression in CD11b DC. Due to the rather low cytokine mRNA expression, marked pulmonary inflammation and the technical possibility of contaminating innate lymphoid cells, further detailed studies using combinations of different methods are required to dissect the cytokine producing capacity of respiratory DC subsets during gramnegative bacterial pneumonia.

The accumulation of functional respiratory pDC during bacterial pneumonia has to the best of our knowledge not been reported so far and raises the question regarding potential novel functions of $\mathrm{pDC}$ in bacterial pneumonia. Respiratory pDC may play a role in tissue repair. Gregorio et al. recently reported, that $\mathrm{pDC}$ accumulate in large numbers in injured skin areas and express 


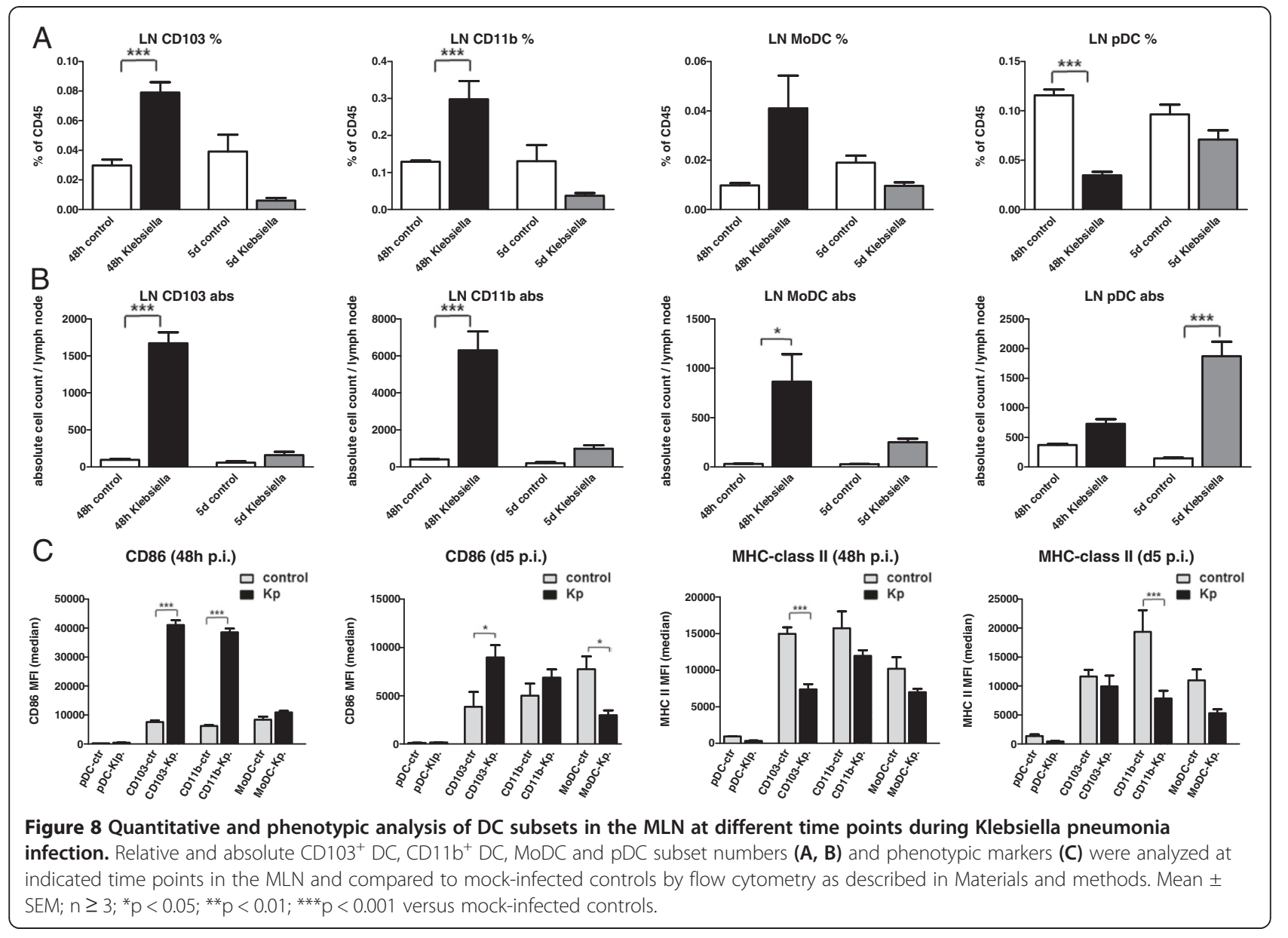

IFN- $\alpha$ [24]. The expression of IFN- $\alpha$ was shown to be related to the detection of self nucleic-acids that were released due to the skin injury. Additionally, it was demonstrated that $\mathrm{pDC}$ depletion significantly delayed wound healing suggesting a functional role for these rare DC subset in tissue repair. Alternatively, accumulation of $\mathrm{pDC}$ in the post acute bacterial pneumonia phase may be related to immunoregulatory functions of these cells. PDC have the capacity to control both CD4+ and CD8+ T cell activation [39]. Antigen presentation to $\mathrm{CD} 4 \mathrm{~T}$ cells via $\mathrm{pDC}$ has been described to inhibit $\mathrm{T}$ helper 1 and $\mathrm{T}$ helper 17 immune responses, suggesting a possible role to prevent $\mathrm{T}$ helper-dependent automimmunity [40]. In a different study using a conditional plasmacytoid depletion model, pDC were demonstrated to play an important role in the stimulation of antiviral $\mathrm{CD}^{+} \mathrm{T}$ cell responses [41].

Our results indicate that Klebsiella pneumonia may exhibit additionally inhibitory effects on DC. The ex vivo analysis of MHC-class II expression on lung DC subsets of Klebsiella pneumonia infected animals consistently indicated decreased MHC-class II expression in comparison to mock-infected controls. This may be related to the recruitement or differentiation of newly arrived DC.
However, analysis of CCR7 migrating DC in the draining MLN during infection additionally indicated decreased MHC-class II expression suggesting Klebsiella pneumoniamediated suppression. Additionally, analysis of the inhibitory molecule CD274 on lung DC during Klebsiella infection revealed a massive upregulation on $\mathrm{CD} 11 \mathrm{~b} \mathrm{DC}$ and MoDC and to a lesser extent on CD103 DC suggesting another pathway of Klebsiella pneumonia-mediated suppression. Klebsiella-mediated induction of inhibitory molecule CD274 on lung DC may be important in limiting antibacterial effector $\mathrm{T}$ cell responses and promoting infectionassociated immunosuppression [42,43]. In this context it would be interesting to establish technologies allowing precise DC subset specific enumeration of bacterial load. Sorting strategies are limited due to a number of technical factors, such as passive bacteria attachment, complex DC phenotype, low DC frequency. Therefore, development of other technologies, such as combination of specific staining of bacterial-related gene products with DC subset markers might be more successful [44].

Our results using ovalbumin-pulsed, Klebsiella pneumoniaestimulated purified $\mathrm{pDC}$ as stimulators of TCR transgenic naive $\mathrm{CD} 4^{+} \mathrm{T}$ cells confirmed the finding, that $\mathrm{pDC}$ 
are not efficient $\mathrm{CD}^{+} \mathrm{T}$ cell stimulators. In direct comparison to other respiratory DC subsets, Klebsiella pneumonia-stimulated $\mathrm{CD}_{103^{+}} \mathrm{DC}$ and CD11b DC represented the most efficient naïve $\mathrm{CD} 4^{+} \mathrm{T}$ cell activators. Moreover, MHC-class II and CD86 surface expression, representing important functional molecules required for MHC-class II restricted $\mathrm{CD} 4$ activation were markedly reduced on respiratory $\mathrm{pDC}$ from Klebsiella-infected animals compared to either $\mathrm{CD} 103^{+}$ DC and CD11b DC. Additionally, analysis of draining MLN during infection revealed rapid relative and absolute accumulation of CD103 DC, CD11b DC and MoDC numbers within 48 h p.i. whereas pDC numbers did exhibit only an absolute increase at d5 p.i. indicating a different role for $\mathrm{T}$ cell activation.

In summary, the present study has revealed marked quantitative and qualitative differences for respiratory DC subsets during sublethal respiratory Klebsiella pneumonia infection. Both the in vivo as well as the in vitro data underline the importance of differentiating respiratory DC subsets during Klebsiella pneumonia. The analysis of lung $\mathrm{DC}$ as a single cell population during infection would have masked many of these differences. Our study highlights that these lung subsets exhibit different migration kinetics, different activatory/regulatory surface molecule expression and different functional CD4 activatory capacity. With respect to the novel finding of increased pDC during Klebsiella infection, future studies are necessary to address the functional role of $\mathrm{pDC}$ during bacterial pneumonia. The use of in vivo DC subset depletion models in future studies will provide additional insight into the relevance of DC subsets for CD4 and CD8 $\mathrm{T}$ effector cell expansion during Klebsiella pneumonia infection.

\section{Additional files}

Additional file 1: Figure S1. Gating strategy and post-sort controls for pDC, MHC-1low CD11 $c^{+}$cells, CD103 DC and CD11b DC. Dotplot staining of sorting gates (A) and post-sort controls with \% cell purity (B) for pDC, MHC-II ${ }^{\text {low }}$ CD11 $c^{+}$cells, CD103 DC and CD11b DC.

Additional file 2: Figure S2. Dissection of DC subsets in the MLN during Klebsiella pneumonia infection. Dotplot staining and gating of MLN CD $103^{+}$DC, CD $11 b^{+}$DC, MoDC and pDC subsets in Klebsiellainfected animals and mock-infected controls. Migratory $\mathrm{CD} 11 \mathrm{C}^{+} \mathrm{CD}_{103^{+}}$ DC, CD $11 \mathrm{~b}^{+} \mathrm{DC}$ and MoDC were identified as MHC-class $\mathrm{II}^{+} \mathrm{CCR} 7^{+}$cells and discriminated according to differential CD103, CD11b, MAR1 and CD64 expression. MLN pDC were identified as CD11 $\mathrm{c}^{+} 120 \mathrm{G} 8^{+} \mathrm{CD} 11 \mathrm{~b}^{\text {neg }}$ cells. Fluorescence minus one controls (FMO) were used for proper identification of $\mathrm{CCR} 7^{+}$and $\mathrm{CD} 64^{+}$populations.

Additional file 3: Figure S3. Maturation control for Klebsiella pneumonia lysate. Lung homogenate was stimulated with indicated concentrations of Kp lysate and median fluorescence intensity (MFI) for CD86 and MHC-II expression was quantitated after $24 \mathrm{~h}$ on CD11 $\mathrm{c}^{+}$Siglec $F^{\text {neg }}$ NK1. $1^{\text {neg }} D C$ by flow cytometry. Mean \pm SEM; $n \geq 3$.

\section{Competing interests}

The authors declare that they have no competing interests.

\section{Authors' contributions}

$H H, N B, J L, G B$ and $S H$ designed the study. HH drafted the manuscript and performed the statistical analysis. NB, AW and SK performed animal experiments. GM, AL and NB performed in vitro immunoassays and expression analysis. OK and AG performed the histopathological analysis. All authors read and approve the final manuscript.

\section{Acknowledgements}

The work was supported by the SFB Transregio 84, German Science Foundation, Innate Immunity of the Lung: Mechanisms of Pathogen Attack and Host Defence in Pneumonia (SFB TR84, Project B3 HH). Additional support was provided by UGMLC (University Gießen and Marburg Lung Center) and Excellence Cluster Cardiopulmonary System (ECCPS). We thank Ms Rebecca Winkler for excellent technical support.

\section{Author details}

${ }^{1}$ Institute for Clinical Immunology and Transfusion Medicine, Justus-Liebig-University Giessen, Member of the German Center for Lung Research (DZL), Langhansstr. 7, D-35392, Giessen, Germany. ${ }^{2}$ Department of Veterinary Pathology, Freie Universität Berlin, Robert-von-Ostertag-Str. 15, 14163, Berlin, Germany. ${ }^{3}$ Department of Internal Medicine II, Klinikstrasse 33, Berlin, Germany.

Received: 4 February 2013 Accepted: 13 September 2013

Published: 17 September 2013

\section{References}

1. Ahmad TA, El-Sayed LH, Haroun M, Hussein AA, El Ashry ESH: Development of immunization trials against Klebsiella pneumoniae. Vaccine 2012, 30:2411-2420.

2. Livermore DM: Current epidemiology and growing resistance of gramnegative pathogens. Korean J Intern Med 2012, 27:128-142.

3. Gupta A: Hospital-acquired infections in the neonatal intensive care unit-Klebsiella pneumoniae. Semin Perinatol 2002, 26:340-345.

4. Matsen JM: The sources of hospital infection. Medicine (Baltimore) 1973, 52:271-277.

5. Jarvis WR, Munn VP, Highsmith AK, Culver DH, Hughes JM: The epidemiology of nosocomial infections caused by Klebsiella pneumoniae. Infect Control 1985, 6:68-74.

6. Yankov IV, Shmilev TI: Ventilator-associated pneumonias in children (I)-diagnostic criteria, etiology and pathogenesis. Folia Med (Plovdiv) 2012, 54:5-11

7. Arnold RS, Thom KA, Sharma S, Phillips M, Kristie Johnson J, Morgan DJ: Emergence of Klebsiella pneumoniae carbapenemase-producing bacteria. South Med J 2011, 104:40-45.

8. Rapp RP, Urban C: Klebsiella pneumoniae carbapenemases in Enterobacteriaceae: history, evolution, and microbiology concerns. Pharmacotherapy 2012, 32:399-407.

9. da Silva RM, Traebert J, Galato D: Klebsiella pneumoniae carbapenemase (KPC)-producing Klebsiella pneumoniae: a review of epidemiological and clinical aspects. Expert Opin Biol Ther 2012, 12:663-671.

10. Chong $Y$, Ito $Y$, Kamimura T: Genetic evolution and clinical impact in extended-spectrum beta-lactamase-producing Escherichia coli and Klebsiella pneumoniae. Infect Genet Evol 2011, 11:1499-1504.

11. Nordmann P, Cuzon G, Naas T: The real threat of Klebsiella pneumoniae carbapenemase-producing bacteria. Lancet Infect Dis 2009, 9:228-236.

12. Banchereau J, Steinman RM: Dendritic cells and the control of immunity. Nature 1998, 392:245-252.

13. Lambrecht BN, Hammad H: Lung dendritic cells in respiratory viral infection and asthma: from protection to immunopathology. Annu Rev Immunol 2012, 30:243-270.

14. Guilliams M, Lambrecht BN, Hammad H: Division of labor between lung dendritic cells and macrophages in the defense against pulmonary infections. Mucosal Immunol 2013, 6:464-473.

15. Kim T, Braciale T: Respiratory dendritic cell subsets differ in their capacity to support the induction of virus-specific cytotoxic CD8+ T cell responses. PLoS One 2009, 4:e4204.

16. Hackstein $\mathrm{H}$, Hagel N, Knoche A, Kranz S, Lohmeyer J, Wulffen W, von Kershaw O, Gruber AD, Bein G, Baal N: Skin TLR7 triggering promotes accumulation of respiratory dendritic cells and natural killer cells. PLOS One 2012, 7:e43320. 
17. Hackstein H, Wachtendorf A, Kranz S, Lohmeyer J, Bein G, Baal N: Heterogeneity of respiratory dendritic cell subsets and lymphocyte populations in inbred mouse strains. Respir Res 2012, 13:94.

18. Unkel B, Hoegner K, Clausen BE, Lewe-Schlosser P, Bodner J, Gattenloehner S, Janssen H, Seeger W, Lohmeyer J, Herold S: Alveolar epithelial cells orchestrate DC function in murine viral pneumonia. J Clin Invest 2012, 122:3652-3664.

19. Plantinga M, Guilliams M, Vanheerswynghels M, Deswarte $K$, Branco-Madeira F, Toussaint W, Vanhoutte L, Neyt K, Killeen N, Malissen B, Hammad H, Lambrecht BN: Conventional and monocyte-derived CD11b(+) dendritic cells initiate and maintain T helper 2 cell-mediated immunity to house dust mite allergen. Immunity 2013, 38:322-335.

20. Siegal FP, Kadowaki N, Shodell M, Fitzgerald-Bocarsly PA, Shah K, Ho S, Antonenko S, Liu YJ: The nature of the principal type 1 interferonproducing cells in human blood. Science 1999, 284:1835-1837.

21. Gilliet $M$, Cao W, Liu Y: Plasmacytoid dendritic cells: sensing nucleic acids in viral infection and autoimmune diseases. Nat Rev Immunol 2008 , 8:594-606.

22. Szabo G, Dolganiuc A: The role of plasmacytoid dendritic cell-derived IFN alpha in antiviral immunity. Crit Rev Immunol 2008, 28:61-94.

23. Bjorck P: The multifaceted murine plasmacytoid dendritic cell. Hum Immunol 2002, 63:1094-1102.

24. Gregorio J, Meller S, Conrad C, Di Nardo A, Homey B, Lauerma A, Arai N, Gallo RL, Digiovanni J, Gilliet M: Plasmacytoid dendritic cells sense skin injury and promote wound healing through type I interferons. J Exp Med 2010, 207:2921-2930.

25. Sung S, Fu S, Rose C, Gaskin F, Ju S, Beaty S: A major lung CD103 (alphaE)-beta7 integrin-positive epithelial dendritic cell population expressing Langerin and tight junction proteins. J Immunol 2006, 176:2161-2172.

26. Ho AWS, Prabhu N, Betts RJ, Ge MQ, Dai X, Hutchinson PE, Lew FC, Wong KL, Hanson BJ, Macary PA, Kemeny DM: Lung CD103+ dendritic cells efficiently transport influenza virus to the lymph node and load viral antigen onto MHC class I for presentation to CD8 T cells. J Immunol 2011, 187:6011-6021.

27. Ivanov S, Fontaine J, Paget C, Macho Fernandez E, van Maele L, Renneson J, Maillet I, Wolf NM, Rial A, Leger H, Ryffel B, Frisch B, Chabalgoity JA, Sirard $J C$, Benecke A, Faveeuw C, Trottein F: Key role for respiratory CD103(+) dendritic cells, IFN-gamma, and IL-17 in protection against Streptococcus pneumoniae infection in response to alphagalactosylceramide. J Infect Dis 2012, 206:723-734.

28. Le B, Etchart N, Goubier A, Lira S, Sirard J, van Rooijen N, Caux C, Ait-Yahia S, Vicari A, Kaiserlian D, Dubois B: Dendritic cells rapidly recruited into epithelial tissues via CCR6/CCL20 are responsible for CD8+ T cell crosspriming in vivo. Immunity 2006, 24:191-201.

29. Leon B, Lopez-Bravo M, Ardavin C: Monocyte-derived dendritic cells formed at the infection site control the induction of protective $T$ helper 1 responses against Leishmania. Immunity 2007, 26:519-531.

30. Furuhashi $K$, Suda T, Hasegawa H, Suzuki $Y$, Hashimoto D, Enomoto N, Fujisawa T, Nakamura Y, Inui N, Shibata K, Nakamura H, Chida K: Mouse Lung CD103+ and CD11bhigh dendritic cells preferentially induce distinct CD4+ T cell responses. Am J Respir Cell Mol Biol 2012, 46:165-172.

31. Herold S, Tabar TS, Janssen H, Hoegner K, Cabanski M, Lewe-Schlosser P, Albrecht J, Driever F, Vadasz I, Seeger W, Steinmueller M, Lohmeyer J: Exudate macrophages attenuate lung injury by the release of IL-1 receptor antagonist in gram-negative pneumonia. Am J Respir Crit Care Med 2011, 183:1380-1390.

32. Hackstein H, Taner T, Zahorchak AF, Morelli AE, Logar AJ, Gessner A, Thomson AW: Rapamycin inhibits IL-4-induced dendritic cell maturation in vitro and dendritic cell mobilization and function in vivo. Blood 2003, 101:4457-4463.

33. Hackstein H, Knoche A, Nockher A, Poeling J, Kubin T, Jurk M, Vollmer J, Bein G: The TLR7/8 ligand resiquimod targets monocyte-derived dendritic cell differentiation via TLR8 and augments functional dendritic cell generation. Cell Immunol 2011, 271:401-412.

34. Ho AWS, Prabhu N, Betts RJ, Ge MQ, Dai X, Hutchinson PE, Lew FC, Wong KL, Hanson BJ, Macary PA, Kemeny DM: Lung CD103+ dendritic cells efficiently transport influenza virus to the lymph node and load viral antigen onto MHC class I for presentation to CD8 T cells. J Immunol 2011, 187:6011-6021.
35. Terrazas CA, Terrazas LI, Gomez-Garcia L: Modulation of dendritic cell responses by parasites: a common strategy to survive. J Biomed Biotechnol 2010, 2010:357106.

36. Bedoui S, Kupz A, Wijburg OL, Walduck AK, Rescigno M, Strugnell RA: Different bacterial pathogens, different strategies, yet the aim is the same: evasion of intestinal dendritic cell recognition. J Immunol 2010, 184:2237-2242.

37. Liu B, Woltman AM, Janssen HLA, Boonstra A: Modulation of dendritic cell function by persistent viruses. J Leukoc Biol 2009, 85:205-214.

38. Kushwah $\mathrm{R}, \mathrm{Hu} \mathrm{J}$ : Complexity of dendritic cell subsets and their function in the host immune system. Immunology 2011, 133:409-419.

39. Takagi H, Fukaya T, Eizumi K, Sato Y, Sato K, Shibazaki A, Otsuka H, Hijikata A, Watanabe T, Ohara O, Kaisho T, Malissen B, Sato K: Plasmacytoid dendritic cells are crucial for the initiation of inflammation and $T$ cell immunity in vivo. Immunity 2011, 35:958-971.

40. Loschko J, Heink S, Hackl D, Dudziak D, Reindl W, Korn T, Krug AB: Antigen targeting to plasmacytoid dendritic cells via Siglec-H inhibits Th celldependent autoimmunity. J Immunol 2011, 187:6346-6356.

41. Swiecki M, Gilfillan S, Vermi W, Wang Y, Colonna M: Plasmacytoid dendritic cell ablation impacts early interferon responses and antiviral NK and CD8(+) T cell accrual. Immunity 2010, 33:955-966.

42. Hotchkiss RS, Monneret G, Payen D: Immunosuppression in sepsis: a novel understanding of the disorder and a new therapeutic approach. Lancet Infect Dis 2013, 13:260-268.

43. Wolfle SJ, Strebovsky J, Bartz H, Sahr A, Arnold C, Kaiser C, Dalpke AH, Heeg K: PD-L1 expression on tolerogenic APCs is controlled by STAT-3. Eur J Immunol 2011, 41:413-424.

44. Sha J, Rosenzweig JA, Kirtley ML, van Lier CJ, Fitts EC, Kozlova EV, Erova TE Tiner BL, Chopra AK: A non-invasive in vivo imaging system to study dissemination of bioluminescent Yersinia pestis CO92 in a mouse model of pneumonic plague. Microb Pathog 2013, 55:39-50.

doi:10.1186/1465-9921-14-91

Cite this article as: Hackstein et al:: Modulation of respiratory dendritic cells during Klebsiella pneumonia infection. Respiratory Research 2013 14:91.

\section{Submit your next manuscript to BioMed Central and take full advantage of:}

- Convenient online submission

- Thorough peer review

- No space constraints or color figure charges

- Immediate publication on acceptance

- Inclusion in PubMed, CAS, Scopus and Google Scholar

- Research which is freely available for redistribution 